\title{
Correlation between brain neurotransmitters and insulin sensitivity: Neuro-preservative role of resveratrol against high fat, high fructose- induced insulin resistance
}

\author{
Rania F. Ahmed ${ }^{1 *}$, Sally A. El Awdan ${ }^{1}$, Gehad A. Abdel Jaleel ${ }^{1}$, Dalia O. Saleh ${ }^{1}$, Omar A.H. Ahmed Farid ${ }^{2}$ \\ 'Department of Pharmacology, Medical division, National Research Centre, (ID: 60014618), Dokki, 12622, Giza, Egypt. \\ ${ }^{2}$ Department of Physiology, National Organization for Drug Control and Research, 12553, Giza, Egypt.
}

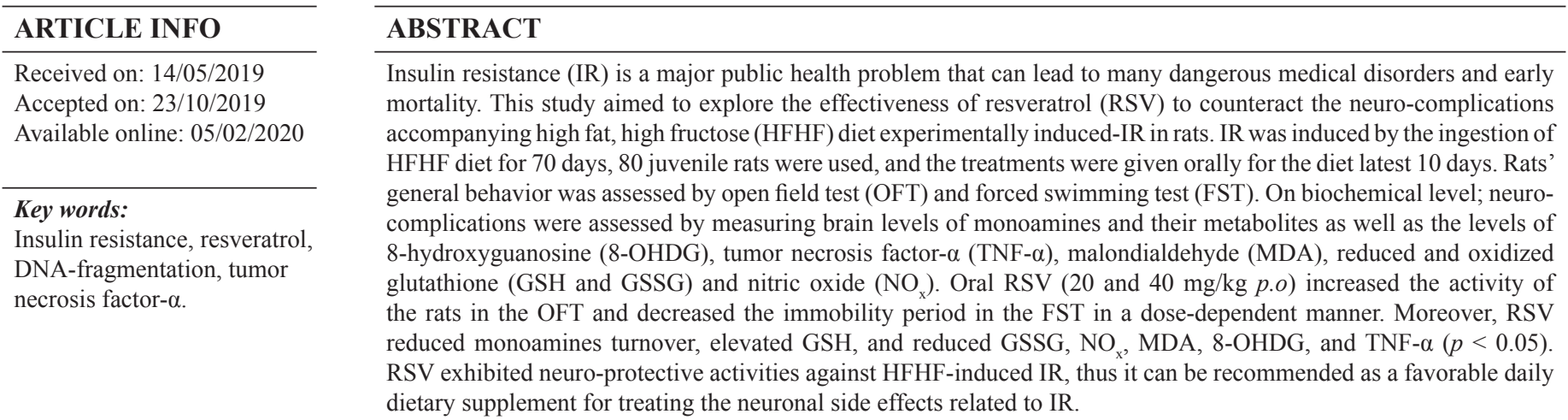

\section{INTRODUCTION}

The incidence of depressive or anxiety disorders is up to $60 \%-80 \%$ higher in patients with type 2 diabetes mellitus (T2DM) than in the healthy population. This could be partially explained by the fact that one of the key precursors of T2DM is the presence of an insulin-resistant state, and previously it was demonstrated that one of the major neurodegenerative disorders that comorbid with insulin resistance (IR) was depression (Kahl et al., 2015; Li et al., 2013; Ryan et al., 2012).

In the last decades, the prevalence of pediatric overweight and obesity has increased reaching $20 \%$ or more in some countries and is frequently associated with impaired IR

"Corresponding Author

Rania F. Ahmed, Department of Pharmacology, National Research Centre, 12622, Giza, Egypt.

E-mail:dr_rania_fouad@Yahoo.com;dr.rania.fouad@gmail.com
(Lalanza et al., 2014). Insulin is a hormone that plays a major role in maintaining the homeostasis between glucose uptake and production. IR is a metabolic condition known to be a state of reduced response to insulin in target tissues, the urge for insulin increases, and the pancreas gradually fails to produce it (Afifi et al., 2017; Kim et al., 2015). The consequences include deficits in energy metabolism, increased inflammation and oxidative stress, and could lead to cellular degeneration and death (De La Monte, 2012). In the central nervous system (CNS), insulin regulates a broad array of functions as cell growth and survival, synapse formation, neurotransmitter function, and plasticity. Chronic IR has adverse consequences on the functional integrity of the CNS, including reduced receptor responsiveness and inhibition of downstream signaling (Arnold et al., 2014).

Oxidative damage plays a vital part in the pathogenesis of IR-induced neuronal degeneration, which highlights the significance of antioxidants in the treatment of IR associated neurodegenerative disorders (Li et al., 2018; Yin et al., 2013). Recently, several dietary supplements have been suggested 
in the management of IR due to their antioxidant and antiinflammatory activities (Bamagous et al., 2018; Sicinska et al., 2015).

Resveratrol (RSV; 3,5,4'-trihydroxystilbene) is a polyphenolic compound with a broad spectrum of pharmacological properties. It has been reported to act as an anti-inflammatory, antioxidant hepatoprotective and neuroprotective (Ahmed-Farid et al., 2016). Evidence abound indicating the usefulness of RSV in the treatment of several metabolic complications including metabolic syndrome, obesity, T2DM, and hyperglycemia (AhmedFarid et al., 2016; Radwan et al., 2016).

The present study investigated the beneficial effects of RSV as a dietary supplement to antagonize the neuro-complications associated with high fat, high fructose diet (HFHF)-induced IR in rats. In addition, metformin (MT) served as a standard antidiabetic drug with neuroprotective potentials.

\section{MATERIAL AND METHODS}

\section{Animals used}

Juvenile 5-weeks-aged male albino rats (Lalanza et al., 2014) weighing 80-90 g were obtained from the animal house at the National Research Centre (NRC, Cairo, Egypt). Animals were then allowed to acclimatize in a quiet room (eight rats/cage), with controlled ambient temperature $\left(22^{\circ} \mathrm{C} \pm 1^{\circ} \mathrm{C}\right)$ and a 12 hours light/ dark cycle, fed a standard diet, and water was provided $a d$ lib. The animals were allocated randomly, whereas each group containing 16 rats/treatment group.

\section{Ethics statement}

This study was achieved according to the recommendations in the Guide for the Care and Use of Laboratory Animals of the National Institutes of Health (NIH No. 85:23 revised 1985) in unity with the guidelines provided by the World Medical Association Declaration of Helsinki on Ethical Principles for studies concerning experimental animals.

\section{Drugs}

Trans-resveratrol (Jing Tea LLC, Australia), as Harmoni-T micronized trans-resveratrol capsules for ingestion were freshly suspended in distilled water prior to oral administration. Metformin hydrochloride tablets (Cid Company, Egypt) were freshly ground and suspended in distilled water just before oral administration.

\section{Experimental design}

High fat, high fructose (HFHF) insulin resistance model

Eighty rats were weighed and allocated in equal groups (16 rats each). One group served as normal control; fed standard diet and tap drinking water. IR was induced in the remaining 64 rats using a high-fat diet; $60 \mathrm{kcal} / 100 \mathrm{kcal}$ saturated fat with $20 \%$ fructose in the drinking water for 60 days (Axelsen et al., 2010). On day 60; rats were fasted overnight and IR was confirmed by computing homeostatic model assessment of insulin resistance (HOMA-IR). HFHF diet-induced insulin-resistant rats were allocated to four groups and were treated as follows: group (1): HFHF control; receiving distilled water $(5 \mathrm{ml} / \mathrm{kg}$; p.o daily), group (2): MT standard group; receiving metformin (MT; 150 $\mathrm{mg} / \mathrm{kg} /$ day; p.o) for 10 consecutive days, group (3): R20 group; receiving RSV (20 mg/kg/day; p.o) for 10 consecutive days, and group (4): R40 group; receiving RSV (40 mg/kg/day; p.o) for 10 consecutive days. In addition to a normal control receiving $5 \mathrm{ml} / \mathrm{kg}$ distilled water/day; p.o). On day 70, eight rats from each group were randomly selected for the conduction of behavioral tests, 1 hour after the last treatments. Twenty-four hours after the last drug ingestions, overnight fasted rats from each group were randomly divided into two subgroups (eight rats each). The first subgroup was used for the collection of blood samples under phenobarbital anesthesia to assess serum; glucose, insulin, and compute the final effect of the treatments on HOMA-IR. The second subgroup was sacrificed by decapitation, for the collection of brain tissues which were then isolated and kept at $80^{\circ} \mathrm{C}$ for further investigation.

\section{Behavioral assessments}

Open field test (OFT)

Open field test was performed in a square wooden arena $(80 \times 80 \times 40 \mathrm{~cm}$ high $)$. The test was conducted according to Ahmed et al. (2014a). Ambulation frequency: number of squares crossed by the animal and rearing frequency: number of times the animal stood stretched on its hind limbs with or without forelimb support were calculated (Ahmed et al., 2014a).

Forced swimming test (FST)

According to Porsolt et al. (1977); forced swimming test was implemented in a cylindrical water tank $(70 \mathrm{~cm}$ high, $40 \mathrm{~cm}$ diameter) (Porsolt et al., 1977).

\section{Biochemical assessments}

Determination of serum fasting levels of glucose and insulin

Serum levels of glucose and insulin were determined spectrophotometrically (Trinder, 1969) and by ELISA kit (Sceti Medical Lab K.K, Tokyo, Japan) (Grassi et al., 1991), respectively. Homeostatic Model Assessment-Insulin Resistance (HOMA-IR) was calculated as follows: HOMA-IR $=[$ Fasting glucose $(\mathrm{mg} / \mathrm{dl}) / 18 *$ Fasting insulin $(\mu \mathrm{IU} / \mathrm{ml})] / 22.5$ (Matthews et al., 1985).

High performance liquid chromatography (HPLC) measurements

All produced chromatogram identified the concentration from the sample in comparison with that of the corresponding standard purchased from Sigma Aldrich.

Determination of brain tissue level of monoamines and their metabolites ( $\mu \mathrm{g} / \mathrm{g}$ tissue) levels

Brain monoamines and their metabolites were detected by high performance liquid chromatography (HPLC) [mobile phase; $20 \mathrm{mM}$ potassium phosphate, $\mathrm{pH}$ 2.5: methanol (99:1), flow rate; $1.5 \mathrm{ml} /$ minute, Ultraviolet (UV); $210 \mathrm{~nm}$ ]. (Pagel et al., 2000). 
Determination of brain tissue reduced glutathione (GSH) ( $\mu \mathrm{mol} / \mathrm{g}$ tissue) and oxidized glutathione (GSSG) ( $\mu \mathrm{mol} / \mathrm{g}$ tissue) levels

The thiols compounds of oxidized and reduced glutathione (GSH and GSSG) were detected by HPLC (mobile phase; $0.0025 \mathrm{M}$ sodium phosphate buffer, $\mathrm{pH} 3.5$, containing $0.005 \mathrm{M}$ tetrabutylammonium phosphate and 13\% methanol, flow rate; $1 \mathrm{ml} /$ minute, UV; $190 \mathrm{~nm}$ ) (Jayatilleke et al., 1993; Yoshida, 1996).

Determination of brain tissue malondialdehyde (MDA) (nmol/g tissue) level

For determination of malondialdehyde (MDA) level; the samples were analyzed using HPLC [mobile phase; 82.5:17.5 (v/v) $30 \mathrm{mM}$ monobasic potassium phosphate ( $\mathrm{pH}$ 3.6)-methanol, flow rate; $1.2 \mathrm{ml} / \mathrm{minute}, \mathrm{UV} ; 250 \mathrm{~nm}$ ] (Karatas et al., 2002; Karatepe, 2004; Lazzarino et al., 1991).

Determination of brain tissue nitric oxide (NOx) ( $\mu$ mol/ $g$ tissue) level

Nitric oxide $\left(\mathrm{NO}_{\mathrm{x}}\right)$ level was determined using HPLC [mobile phase; mixture of $0.1 \mathrm{M} \mathrm{NaCl}-$ methanol (45:55), flow rate; $2 \mathrm{ml} /$ minute, UV; $230 \mathrm{~nm}$ ] (Papadoyannis et al., 1999).

Determination of brain tissue 8-hydroxyguanosine (8-OHDG) (pg/g tissue) level

The separation of 8-OHDG was performed with HPLC [eluting solution; $\mathrm{H}_{2} \mathrm{O} /$ methanol at a ratio $(85: 15)$ with 50 $\mathrm{mM} \mathrm{KH} \mathrm{PO}_{4}$, pH 5.5; flow rate; $0.68 \mathrm{ml} /$ minute, UV; $\left.245 \mathrm{~nm}\right]$ (Lodovici et al., 1997).

Determination of brain tissue level of tumor necrosis factor alpha (TNF- $\alpha)(p g / g$ tissue)

Brain tissue level of tumor necrosis factor alpha (TNF- $\alpha$ ) was determined with ELISA kit (Raybiotech) (Bonavida, 1991).

\section{Statistical Analysis}

Statistical analysis was performed by non-parametric $\mathrm{K}$ independent samples Kruskal-Wallis test then Dunn's multiple comparisons test for the open field test (OFT) was performed. Comparisons between means for all other parameters were performed using one-way analysis of variance followed by Tukey's multiple comparisons test at $p<0.05$. GraphPad

Table 1. Effects of resveratrol on open field test parameters.

\begin{tabular}{lcc}
\hline Groups & Ambulation (Count/ 5 minutes) & Rearing (Count/5 minutes) \\
\hline Normal & $43.75 \pm 2.52$ & $24.5 \pm 1.04$ \\
HFHF & $25.5 \pm 1.88^{*}$ & $10.75 \pm 0.88^{*}$ \\
Metformin & $45.5 \pm 2.26^{@}$ & $23.63 \pm 1.57^{@}$ \\
R20 & $39.13 \pm 2.59$ & $19.5 \pm 0.63$ \\
R40 & $47.75 \pm 2.39^{@}$ & $25.63 \pm 1.00^{@}$ \\
\hline
\end{tabular}

Significantly different from the normal control group, ${ }^{\circledR}$ significantly different from HFHF control group at $p<0.05$.
Prism software (version 6) was used and values were expressed as Mean \pm SE. Where ${ }^{*}$ significantly different from the normal control group, ${ }^{@}$ significantly different from HFHF control group at $p<0.05$.

\section{RESULTS}

\section{Behavioral assessments}

Effects on open field test parameters

Adding HFHF to the diet of rats resulted in a significant reduction in both ambulation and rearing frequencies in comparison with normal control. RSV $(20 \mathrm{mg} / \mathrm{kg})$ resulted in a slight increase in both frequencies yet results obtained were statistically nonsignificant from the HFHF group. On the other hand, RSV (40 $\mathrm{mg} / \mathrm{kg}$ ) normalized both frequencies and the results were nearly equivalent to those of MT (Table 1).

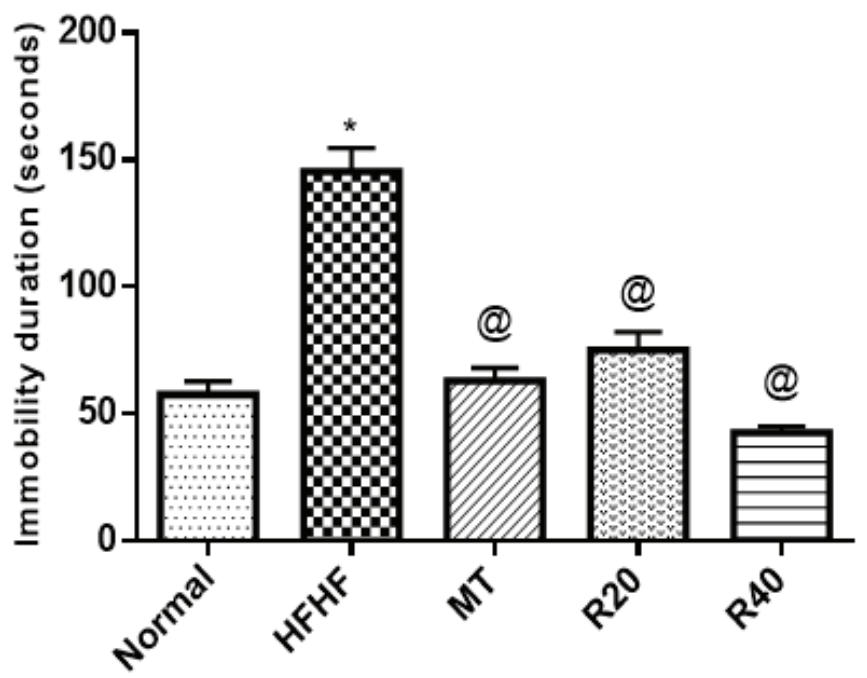

Figure 1. Effect of resveratrol on the immobility period in the forced swimming test. "Significantly different from normal control group, ${ }^{\circledR}$ significantly different from the HFHF control group at $p<0.05$.

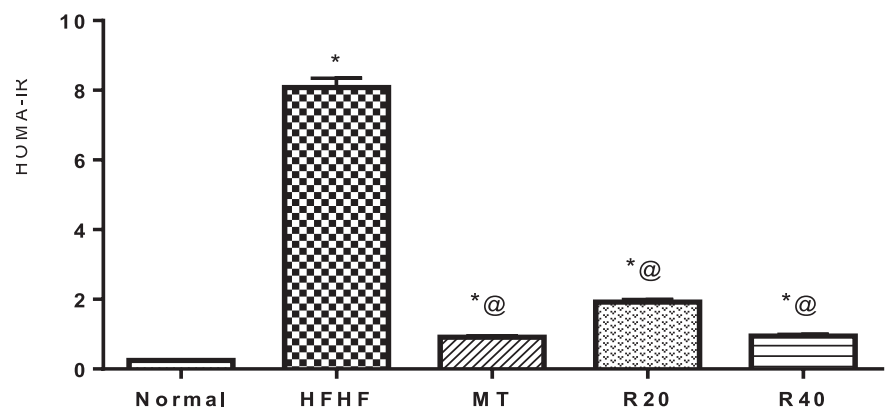

Figure 2. Effect of resveratrol on serum HOMA-IR. "Significantly different from the normal control group, ${ }^{\circledR}$ significantly different from the HFHF control group at $p<0.05$. 
Effects on immobility period in the forced swimming test

Adding HFHF to the diet of rats resulted in a significant elevation in the immobility period in the forced swimming test $($ FST) $(145.4 \pm 9.18$ seconds vs. $57.5 \pm 5.18$ seconds) in comparison with normal control. RSV dosedependently resulted in a significant decrease in the immobility period $(75.00 \pm 7.32$ seconds and $42.5 \pm 2.50$ seconds vs. 145.4 \pm 9.18 seconds), respectively, when compared with HFHF control group and the outcomes of the high dose approached those of MT (Fig. 1).

\section{Effects on serum HOMA-IR}

High fat, high fructose diet group significantly elevated HOMA-IR when compared to the normal control group. Treatment with RSV dose-dependently reduced HOMA-IR in comparison with the HFHF control. The higher dose of RSV outcomes was similar to MT (Fig. 2).

\section{Effects on brain monoamines and their metabolites}

Adding HFHF to diet to rats significantly increased serotonin [5-hydroxytryptamine (5-HT)] and dopamine (DA) turn over in comparison with normal control where both 5-HT and DA levels were decreased and the levels of their metabolites; 5-hydroxyindoleacetic acid, 3,4-dihydroxyphenylacetic acid, and homovanillic acid were increased. Furthermore, the DA/ norepinephrine (NE) ratio was shifted toward the NE side. R20 and R40 significantly reduced 5-HT and DA turn over and shifted the DA/NE ratio toward the formation of DA in comparison with HFHF control while the effect of the higher dose reached that of MT (Fig. 3).
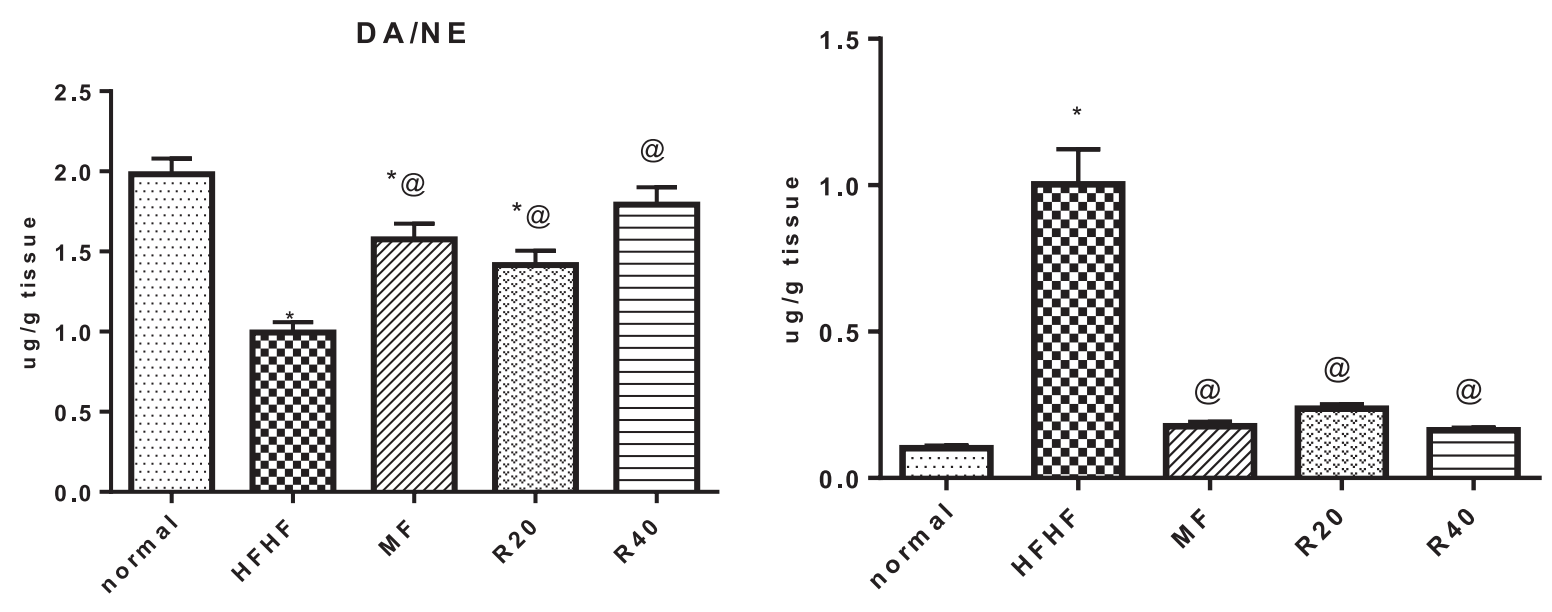

HVA/D A
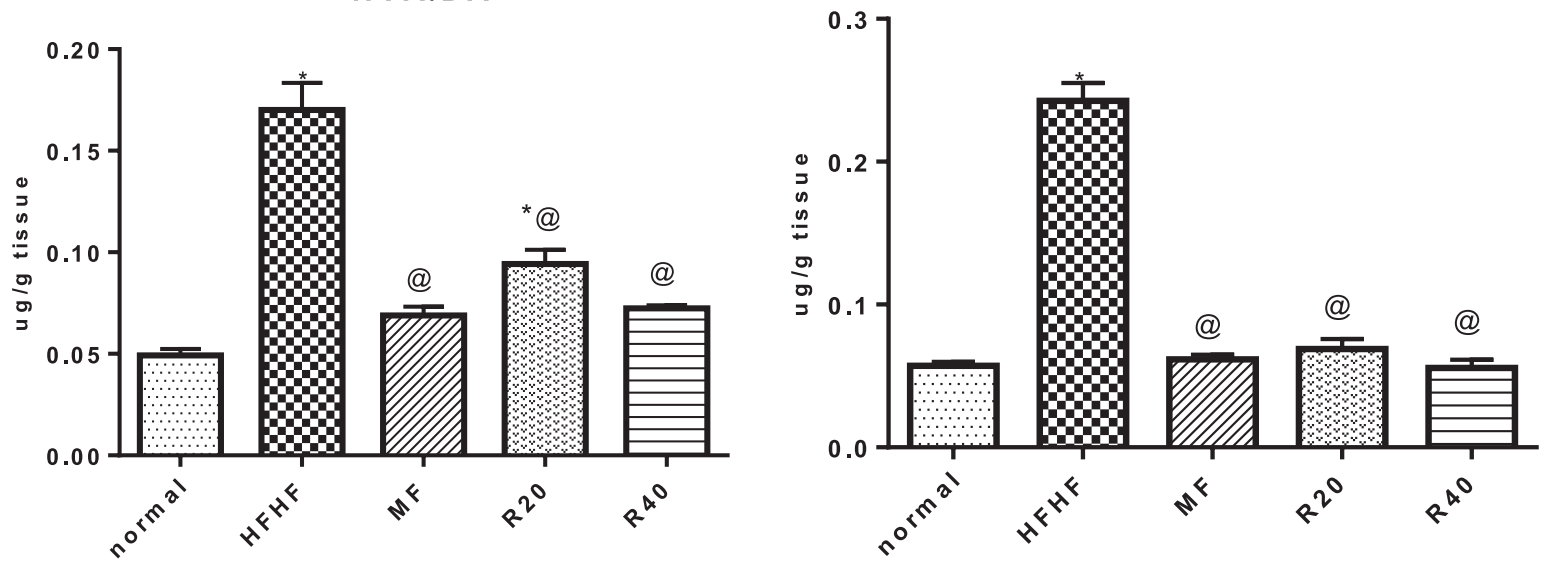

Figure 3. Effect of resveratrol on brain monoamines turnover. "Significantly different from the normal control group, ${ }^{@}$ significantly different from the HFHF control group at $p<0.05$. 
Table 2. Effects of resveratrol on brain oxidative and nitrosative stresses.

\begin{tabular}{lccc}
\hline Groups & MDA (nmol/g) & NOx (umol/g) & GSSG/GSH (umol/g) \\
\hline Normal & $68.23 \pm 1.37$ & $29.53 \pm 0.64^{@}$ & $0.103 \pm 0.003$ \\
HFHF & $111.9 \pm 3.39^{*}$ & $42.89 \pm 1.15^{*}$ & $0.258 \pm 0.01^{*}$ \\
Metformin & $82.1 \pm 1.35^{*}$ & $34.19 \pm 0.55^{*} @$ & $0.162 \pm 0.005^{*}$ \\
R20 & $88.38 \pm 1.76^{*} @$ & $38.96 \pm 0.59^{*} @$ & $0.172 \pm 0.003^{*} @$ \\
R40 & $78.88 \pm 1.92^{*} @$ & $32.32 \pm 0.76^{@}$ & $0.151 \pm 0.004^{*} @$ \\
\hline
\end{tabular}

"Significantly different from the normal control group, ${ }^{{ } \text {significantly different from HFHF }}$ control group at $p<0.05$.

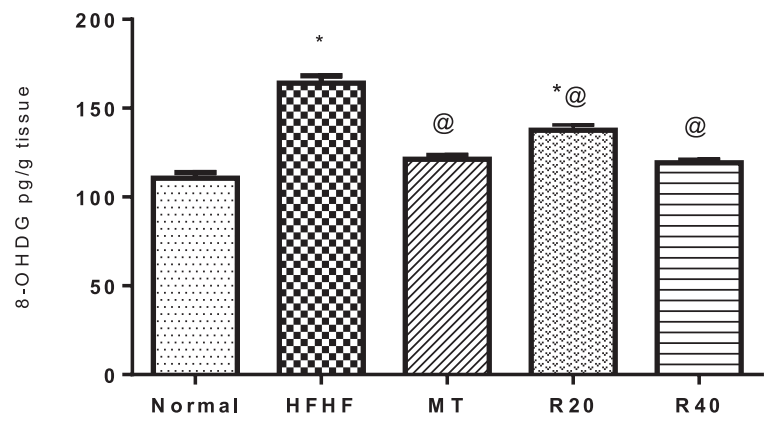

Figure 4. Effect of resveratrol on brain tissue level of 8-OHDG. "Significantly different from the normal control group, ${ }^{\circledR}$ significantly different from the HFHF control group at $p<0.05$.

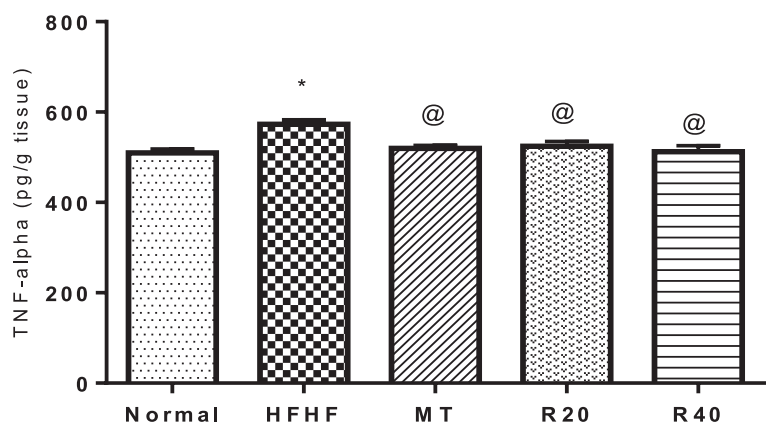

Figure 5. Effect of resveratrol on brain tissue level of tumor necrosis factor alpha (TNF- $\alpha)$. "Significantly different from the normal control group, ${ }^{\circledR}$ significantly different from HFHF control group at $p<0.05$.

\section{Effects on brain oxidative and nitrosative stresses}

Insulin resistance resulted in a significant elevation in MDA and NOx levels as well as GSSG/GSH ratio indicating pronounced oxidative and nitrosative stresses in comparison with normal control. RSV dose-dependently reduced both the oxidative and nitrosative stresses (Table 2).

\section{Effects on brain tissue level of 8-OHDG}

Insulin resistance significantly increased the brain tissue level of 8-OHDG indicating pronounced DNA fragmentation $(164.1 \pm 4.14$ vs. $110.6 \pm 3.13 \mathrm{pg} / \mathrm{g}$ tissue $)$ when compared with the normal control group. RSV at the low dose decreased 8-OHDG level $(137.6 \pm 3.00$ vs. $164.1 \pm 4.14 \mathrm{pg} / \mathrm{g}$ tissue $)$ in comparison with the HFHF group. Moreover, RSV at the high dose-normalized 8-OHDG level which was comparable to those of MT (Fig. 4).

\section{Effects on brain tissue level of tumor necrosis factor alpha (TNF- $\alpha)$}

HFHF-induced IR prominently elevated in the brain tissue TNF- $\alpha$ level $(573.1 \pm 7.91$ vs. $509.8 \pm 6.33 \mathrm{pg} / \mathrm{g}$ tissue $)$ in comparison with normal control. RSV at the two dose levels normalized TNF- $\alpha$ level $(524.6 \pm 10.22$ and $512.6 \pm 13.25 \mathrm{pg} / \mathrm{g}$ tissue), respectively (Fig. 5).

\section{Pearson's correlations studies}

Correlation studies demonstrated that there was a direct significant positive correlation between HOMA-IR and the increased TNF- $\alpha$ level, 8-OHDG in addition to oxidative and nitrosative stresses. Moreover, there was a negative correlation between HOMA-IR and DA as well as serotonin levels. TNF- $\alpha$ proved to be negatively correlated to the serotonin level. 8-OHDG exhibited a negative correlation with both DA and serotonin levels and positive correlation to oxidative and nitrosative stresses. Finally, oxidative and nitrosative stresses were negatively correlated to both DA and serotonin levels (Table 3, Fig. 6).

Table 3. Pearson's correlations studies.

\begin{tabular}{|c|c|c|c|c|c|c|c|c|c|}
\hline & TNF- $\alpha$ & 8-OHDG & DA & Serotonin & MDA & NO & GSH & GSSG & HOMA \\
\hline HOMA & $0.668^{* * *}$ & $0.880^{* * *}$ & $-0.533^{*}$ & $-0.924^{* * *}$ & $0.886^{* * *}$ & $0.784^{* *}$ & $-0.660^{* *}$ & $0.838^{* * *}$ & NA \\
\hline TNF- $\alpha$ & NA & $0.614^{* *}$ & -0.326 & $-0.647^{* *}$ & $0.667^{* *}$ & $0.473^{*}$ & -0.364 & $0.587^{*}$ & $0.668^{* * *}$ \\
\hline 8-OHDG & $0.614^{* *}$ & NA & $-0.607^{* * *}$ & $-0.814^{* * *}$ & $0.810^{* * * *}$ & $0.891^{* * *}$ & $-0.647^{* *}$ & $0.809^{* * *}$ & $0.880^{* * *}$ \\
\hline MDA & $0.667^{* * *}$ & $0.810^{* * * *}$ & $-0.653^{* *}$ & $-0.804^{* * *}$ & NA & $0.802^{* * *}$ & $-0.683^{* *}$ & $0.892^{* * *}$ & $0.886^{* * *}$ \\
\hline NO & $0.473^{*}$ & $0.891^{* * *}$ & $-0.648^{* *}$ & $-0.716^{* * *}$ & $0.802^{* * *}$ & NA & $-0.616^{* *}$ & $0.796^{* *}$ & $0.784^{* *}$ \\
\hline GSH & -0.364 & $-0.647^{* *}$ & $0.886^{* * * *}$ & $0.585^{* *}$ & $-0.683^{* *}$ & $-0.616^{* *}$ & NA & $-0.646^{* *}$ & $-0.660^{* *}$ \\
\hline GSSG & $0.587^{*}$ & $0.809^{* * * *}$ & $-0.617^{* *}$ & $-0.836^{* * *}$ & $0.892^{* * * *}$ & $0.796^{* *}$ & $-0.646^{* *}$ & NA & $0.838^{* * *}$ \\
\hline DA & -0.326 & $-0.607^{* *}$ & NA & $0.428^{*}$ & $-0.653^{* *}$ & $-0.648^{* *}$ & $0.886^{* * *}$ & $-0.617^{* *}$ & $-0.533^{*}$ \\
\hline Serotonin & $-0.647^{* * *}$ & $-0.814^{* * *}$ & $0.428^{*}$ & NA & $-0.804^{* * * *}$ & $-0.716^{* *}$ & $0.585^{* *}$ & $-0.836^{* * * *}$ & $-0.924^{* * * *}$ \\
\hline
\end{tabular}

Significant correlation at $(p<0.05)^{*},(p<0.01)^{* *},(p<0.001)^{* * *} .-=$ negative correlation, NA $=$ non-applicable correlation. 

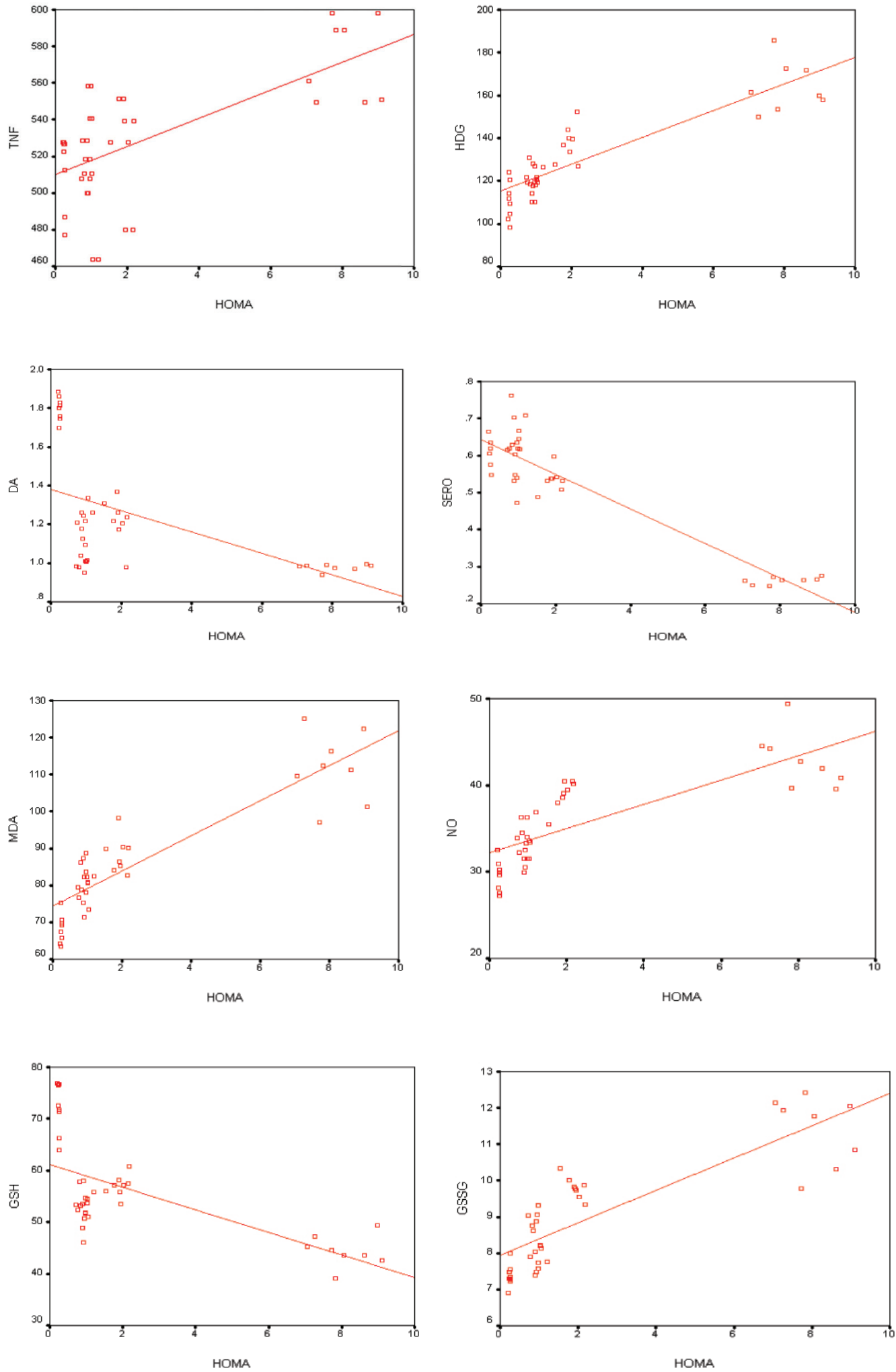

Figure 6. (Continued). 

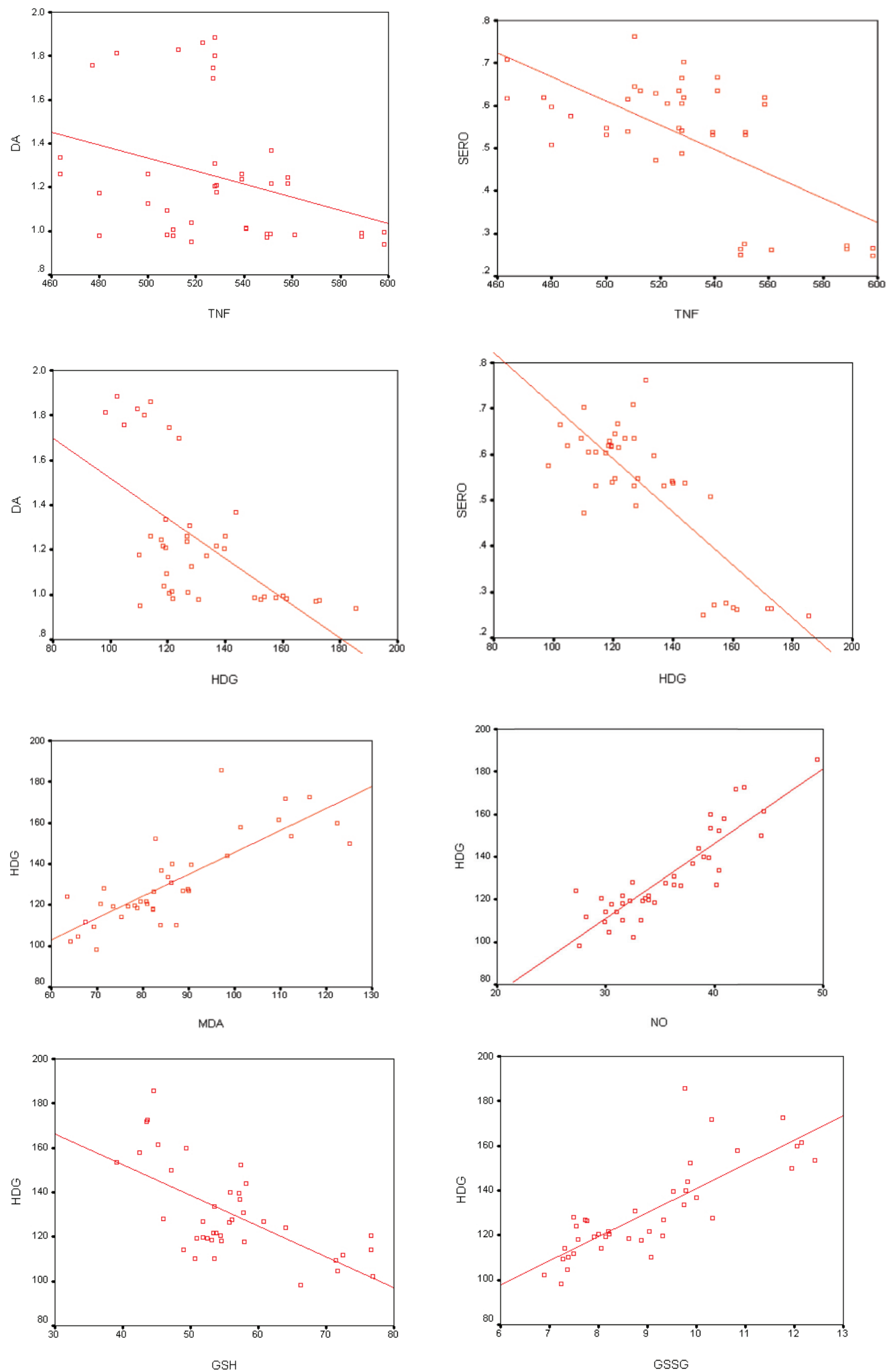

Figure 6. (Continued). 

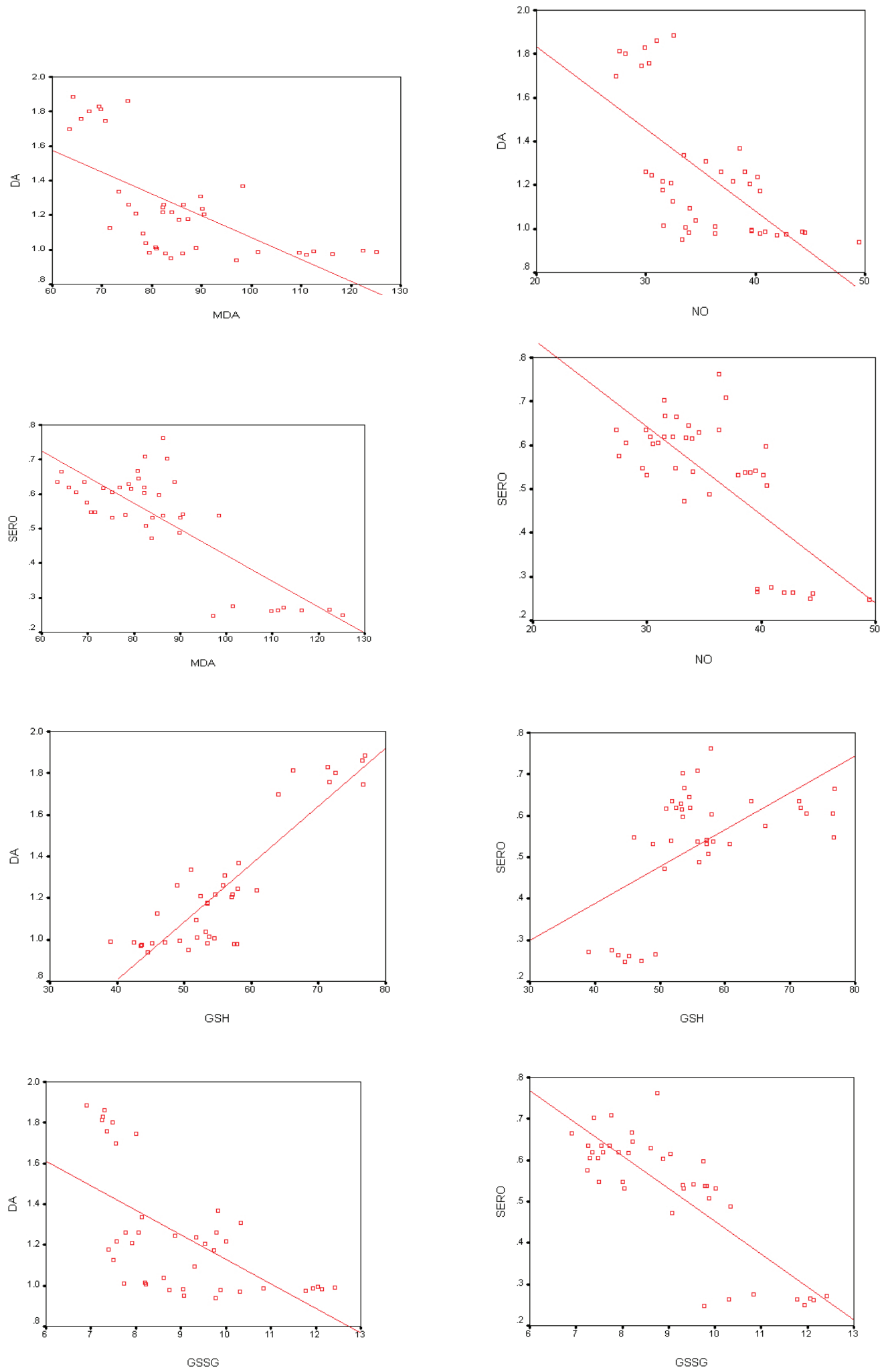

Figure 6. Correlation graphs.

\section{DISCUSSION}

As formerly reported; high fat in association with high fructose intake is linked to metabolic disturbances including IR, hypertriglyceridemia, dyslipidemia, in addition to hepatic

steatosis. It was previously demonstrated that in dietary animal models of IR associated with very high-fat feeding; animals had significantly higher plasma insulin and marked increase in hepatic lipid levels compared to the control group fed with a standard diet. 
Furthermore; it is well established that dietary intake high in fat and fructose triggers the explosion of free radicals and depletion of the antioxidant levels, thereby generating a redox imbalance, thus resulting in oxidative and nitrosative stresses in all body organs (Lozano et al., 2016; Rodriguez Lanzi et al., 2016). These resultant oxidative and nitrosative stresses accelerate oxidative DNA damage through amplification of lipid peroxidation in addition to the progression of structural and functional deformities in the cellular membrane as well as the intracellular biomolecules, organelles, and enzymes (D'Archivio et al., 2012; Fisher-Wellman et al., 2009). Formation of 8-hydroxy-2deoxyguanosine (8-OHDG) adducts as a result of DNA oxidative hydroxylation could be a reliable oxidative DNA impairment and repair biomarker (Abdelali et al., 2016; Aksit et al., 2014).

As previously stated, depression is one of the most hazardous neurodegenerative disorders that has been implicated with IR as it could influence depression by several mechanisms, keeping in consideration the fact those variations in the activity of DA and/or serotonin systems have been correlated to depression; IR was previously proposed to disturb CNS serotonin (5-hydroxytryptamine; 5-HT) synthesis and decrease receptor affinity. On the other hand; IR has been reported to differ inversely with brain serotonergic activity. Moreover; multiple animal studies demonstrated metabolic improvements in IR models after the administration of DA agonists including significant weight loss, decreased levels of glucose along with increased glucose tolerance and decreased IR (Muldoon et al., 2006; Scranton and Cincotta, 2010). Furthermore; IR is accompanied with elevated inflammation and thereby cytokine outflow in some brain regions resulting in neuro-inflammation; a condition that could predispose depression by itself (Kleinridders et al., 2015; Wong et al., 2016). It was previously demonstrated that decreased depressive symptoms have been associated with inhibition of the inflammatory cytokine tumor necrosis factor (TNF- $\alpha$ ) in depressed patients with elevated inflammation (Weinberger et al., 2015).

Metformin is a well-known anti-diabetic drug that is used in the management of IR. In the CNS, MT possesses antioxidant and neuroprotective activities and avoids the neurodegenerative alterations, thus the neuronal signaling system is restored (El-Mir et al., 2008).

Resveratrol is one of the most popular nutraceuticals that proved to have antioxidant, anti-inflammatory, antidepressant, and general neuroprotective properties (Ahmed et al., 2014b; Radwan et al., 2016). The neuroprotection of RSV on neural damages in various models has been well characterized. Several evidences have shown that RSV could exert a neuroprotective effect against ischemia, seizure, and many other neurodegenerative diseases. RSV ingestion in several stress and depression models reversed behavioral performance deficits and produced a marked increase of brain 5-HT, NE, and DA levels (Ahmed et al., 2014a). Moreover; increasing lines of evidence show that RSV exhibits cytoprotective actions and could influence DNA repair (AhmedFarid et al., 2016; Okawara et al., 2007). Increasing interest has focused on the possibility of the existence of a connection between RSV's anti-inflammatory and antioxidant potentials and neuroprotective properties. Previous investigators reported that RSV exhibited beneficial neuroprotective properties in several neurodegenerative models through up-regulating the antioxidant status, decreasing reactive oxygen species production, and attenuating the stimulation of immune cells and thus releasing of inflammatory mediators (Khan et al., 2010; Zhang et al., 2010). In addition; it was demonstrated that RSV improved insulin action in animals with experimentally induced IR. Furthermore; it showed advantageous actions against the neuro-complications associated with streptozotocin-induced diabetes in rats (Sadi and Konat, 2016; Szkudelski et al., 2015). Former studies in our laboratory revealed that the hepatic complications resulting from IR induced in rats by HFHF diet could be ameliorated by oral administration of RSV evidenced by the reduction in HOMA-IR, hepatic high affinity insulin receptors and low affinity insulin receptors expression, total cholesterol, triglycerides, TNF- $\alpha$ levels, as well as the serum aspartate aminotransferase and alanine aminotransferase. Furthermore, it counteracted the redox imbalance and exhibited hepatic DNA preservation potential (Saleh et al., 2017).

Therefore, the aim of our study was to investigate the possible neuroprotective role of RSV against the depression symptoms that could be associated with HFHF-induced IR compared to MT as a standard anti-diabetic drug with neuroprotective potential.

Correlation studies demonstrated that increased HOMAIR, TNF- $\alpha, 8$-OHDG levels, oxidative and nitrosative stresses were positively correlated. In addition, each one of these was individually negatively correlated to DA and serotonin levels.

Our study revealed that HFHF resulted in pronounced IR represented by significantly elevated HOMA-IR. Regarding the neuro-complications associated with IR in respect to animal behavior, our findings demonstrated that HFHF resulted in impairment in normal behavior designated by decreased ambulation and rearing frequencies in the OFT and increased immobility period in the FST. Concerning the biochemical parameters measured, there was an increase in monoamines turn over in addition to increased oxidative, nitrosative stresses, and $\mathrm{TNF}-\alpha$ content as well as neuronal tissue degeneration represented by an elevated level of 8-OHDG.

Results of our study demonstrated that the ingestion of RSV improved the HFHF-induced insulin-resistant state where serum HOMA-IR was reduced. It reversed the impaired behavior in the OFT and decreased the immobility period in the FST. Moreover, brain monoamines turn over decreased; serotonin level was normalized, and the DA/NE ratio was shifted toward the DA side which could be responsible in part to the advantageous effect of RSV in ameliorating the insulin-resistant state. In addition, TNF- $\alpha$ level was reduced indicating the antiinflammatory effect which in turn could be a contribution to the antidepressant mechanism of action. Finally, 8-OHDG content was lowered designating DNA preservation potential. The results were comparable to and sometimes superior over those of MT.

\section{CONCLUSION}

The present data indicate the antidepressant and neuropreservation potential of RSV against the neuro-complications associated with HFHF-induced IR.

\section{LIST OF ABBREVIATIONS}

$\mathrm{ALT}=$ alanine aminotransferase, $\mathrm{AST}=$ aspartate aminotransferase, $\mathrm{DA}=$ dopamine, $\mathrm{GSH}=$ reduced glutathione, GSSG = oxidized glutathione, HAIR = high 
affinity insulin receptors, $\mathrm{HFHF}=$ high fat high fructose, HOMA-IR $=$ homeostatic model assessment of insulin resistance), HPLC = high-performance liquid chromatography, IR= insulin resistance, $\mathrm{LAIR}=$ low affinity insulin receptors, MDA= malondialdehyde, $\mathrm{NE}=$ norepinephrine, $\mathrm{NOx}=$ nitric oxide; nitrate + nitrite, $\mathrm{ROS}=$ reactive oxygen species, $\mathrm{TNF}-\alpha=$ tumor necrosis factor- $\alpha, 5-\mathrm{HT}=$ serotonin, 8 -hydroxyguanosine $=8$-OHDG.

\section{CONFLICT OF INTEREST}

The authors declare that they have no conflicts of interest.

\section{FINANCIAL SUPPORT}

for the research.

The authors declared that there are no sources of funding

\section{AUTHORS' CONTRIBUTION}

All authors contributed to the conception and design of the work. Dr. Rania F. Ahmed conducted behavioral studies. Biochemical parameters were conducted by Dr. Rania F. Ahmed, Dr. Sally A. El Awdan, Dr. Gehad A. Abdel Jaleel, Dr. Dalia O. Saleh, and Dr. Omar A.H. Ahmed-Farid. All authors contributed to the analysis and interpretation of data for the work, drafting the work, and revising it critically for important intellectual content.

\section{REFERENCES}

Abdelali A, Al-Bader M, Kilarkaje N. Effects of TransResveratrol on hyperglycemia-induced abnormal spermatogenesis, DNA damage and alterations in poly (ADP-ribose) polymerase signaling in rat testis. Toxicol Appl Pharmacol, 2016; 311:61-73.

Afifi NA, Ramadan A, Erian EY, Saleh DO, Sedik AA, Badawi M, El Hotaby W. Trigonelline attenuates hepatic complications and molecular alterations in high-fat high-fructose diet-induced insulin resistance in rats. Can J Physiol Pharmacol, 2017; 95(4):427-36.

Ahmed-Farid O, Ahmed R, Saleh D. Combination of resveratrol and fluoxetine in an acute model of depression in mice: prevention of oxidative DNA fragmentation and monoamines degradation. J Appl Pharm Sci, 2016; 6(6): 1-7.

Ahmed R, Abdel-Rahman R, Abdallah H, Saleh D, Farid O, Hessin A. Antidepressant-like effect of resveratrol in a subchronic model of depression. J Arab Soc Med Res, 2014a; 9(2):48-53.

Ahmed RF, Abdel-Rahman RF, Farid OAHA, El-Marasy SA, Hessin AF. Combined hepatoprotective and antidepressant effects of resveratrol in an acute model of depression. Bull Fac Pharm Cairo Univ, 2014b; 52(2):191-7.

Aksit H, Bildik A. Determination of DNA damage in experimental liver intoxication and role of $\mathrm{N}$-acetyl cysteine. Cell Biochem Biophys, 2014; 70(2):1119-25.

Arnold SE, Lucki I, Brookshire BR, Carlson GC, Browne CA, Kazi H, Bang S, Choi BR, Chen Y, McMullen MF, Kim SF. High fat diet produces brain insulin resistance, synaptodendritic abnormalities and altered behavior in mice. Neurobiol Dis, 2014; 67:79-87.

Axelsen LN, Pedersen HD, Petersen JS, Holstein-Rathlou NH, Kjolbye AL. Metabolic and cardiac changes in high cholesterol-fructosefed rats. J Pharmacol Toxicol Methods, 2010; 61(3):292-6.

Bamagous G, Al Ghamdi S, Aziz Ibrahim I, Mahfoz A, Afify M, Alsugoor M, Shammah A, Arulselvan P, Rengarajan T. Antidiabetic and antioxidant activity of ethyl acetate extract fraction of Moringa oleifera leaves in streptozotocin-induced diabetes rats via inhibition of inflammatory mediators. Asian Pac J Trop Biomed, 2018; 8(6):320-7.

Bonavida B. Immunomodulatory effect of tumor necrosis factor. Biotherapy, 1991; 3(2):127-33.

D'Archivio M, Annuzzi G, Vari R, Filesi C, Giacco R, Scazzocchio B, Santangelo C, Giovannini C, Rivellese AA, Masella R. Predominant role of obesity/insulin resistance in oxidative stress development. Eur J Clin Invest, 2012; 42(1):70-8.De La Monte SM. Metabolic derangements mediate cognitive impairment and Alzheimer's disease: role of peripheral insulin-resistance diseases. Panminerva Med, 2012; 54(3):171-8.

El-Mir MY, Detaille D, G RV, Delgado-Esteban M, Guigas B, Attia S, Fontaine E, Almeida A, Leverve X. Neuroprotective role of antidiabetic drug metformin against apoptotic cell death in primary cortical neurons. J Mol Neurosci, 2008; 34(1):77-87.

Fisher-Wellman K, Bloomer RJ. Macronutrient specific postprandial oxidative stress: relevance to the development of insulin resistance. Curr Diabetes Rev, 2009; 5(4):228-38.

Grassi J, Pradelles P. Compounds labelled by the acetylcholinesterase of Electrophorus Electricus. Its preparation process and its use as a tracer or marquer in enzymo-immunological determinations. US Patent N1,047,330, 1991.

Jayatilleke E, Shaw S. A high-performance liquid chromatographic assay for reduced and oxidized glutathione in biological samples. Anal Biochem 1993; 214(2):452-7.

Kahl KG, Schweiger U, Correll C, Muller C, Busch ML, Bauer M, Schwarz P. Depression, anxiety disorders, and metabolic syndrome in a population at risk for type 2 diabetes mellitus. Brain Behav, 2015; 5(3):e00306.

Karatas F, Karatepe M, Baysar A. Determination of free malondialdehyde in human serum by high-performance liquid chromatography. Anal Biochem, 2002; 311(1):76-9.

Karatepe M. Simultaneous determination of ascorbic acid and free malondialdehyde in human serum by HPLC-UV. LCGC Asia Pac, 2004; 7(2):36-8.

Khan MM, Ahmad A, Ishrat T, Khan MB, Hoda MN, Khuwaja G, Raza SS, Khan A, Javed H, Vaibhav K, Islam F. Resveratrol attenuates 6-hydroxydopamine-induced oxidative damage and dopamine depletion in rat model of Parkinson's disease. Brain Res, 2010; 1328:139-51.

Kim B, Feldman EL. Insulin resistance as a key link for the increased risk of cognitive impairment in the metabolic syndrome. Exp Mol Med, 2015; 47:e149.

Kleinridders A, Cai W, Cappellucci L, Ghazarian A, Collins WR, Vienberg SG, Pothos EN, Kahn CR. Insulin resistance in brain alters dopamine turnover and causes behavioral disorders. Proc Natl Acad Sci U S A, 2015; 112(11):3463-8.

Lalanza JF, Caimari A, del Bas JM, Torregrosa D, Cigarroa I, Pallas M, Capdevila L, Arola L, Escorihuela RM. Effects of a post-weaning cafeteria diet in young rats: metabolic syndrome, reduced activity and low anxiety-like behaviour. PLoS One, 2014; 9(1):e85049.

Lazzarino G, Di Pierro D, Tavazzi B, Cerroni L, Giardina B. Simultaneous separation of malondialdehyde, ascorbic acid, and adenine nucleotide derivatives from biological samples by ion-pairing highperformance liquid chromatography. Anal Biochem, 1991; 197(1):191-6.

Li L, Li X, Zhou W, Messina JL. Acute psychological stress results in the rapid development of insulin resistance. J Endocrinol, 2013; 217(2):175-84.

Li W-N, Han H, Jing Z-Y, Yang X-H, Zhang Y, Wei J-L. Mitochondrial oxidative damage and apoptosis induced by high glucose through Rho kinase signal pathway in renal tubular epithelial cells. Asian Pac J Trop Med, 2018; 11(6):399-404.

Lodovici M, Casalini C, Briani C, Dolara P. Oxidative liver DNA damage in rats treated with pesticide mixtures. Toxicology, 1997; 117(1):55-60.

Lozano I, Van der Werf R, Bietiger W, Seyfritz E, Peronet C, Pinget M, Jeandidier N, Maillard E, Marchioni E, Sigrist S, Dal S. Highfructose and high-fat diet-induced disorders in rats: impact on diabetes risk, hepatic and vascular complications. Nutr Metab (Lond), 2016; 13:15.

Matthews DR, Hosker JP, Rudenski AS, Naylor BA, Treacher DF, Turner RC. Homeostasis model assessment: insulin resistance and betacell function from fasting plasma glucose and insulin concentrations in man. Diabetologia, 1985; 28(7):412-9.

Muldoon MF, Mackey RH, Korytkowski MT, Flory JD, Pollock BG, Manuck SB. The metabolic syndrome is associated with reduced 
central serotonergic responsivity in healthy community volunteers. J Clin Endocrinol Metab, 2006; 91(2):718-21.

Okawara M, Katsuki H, Kurimoto E, Shibata H, Kume T, Akaike A. Resveratrol protects dopaminergic neurons in midbrain slice culture from multiple insults. Biochem Pharmacol, 2007; 73(4):550-60.

Pagel P, Blome J, Wolf HU. High-performance liquid chromatographic separation and measurement of various biogenic compounds possibly involved in the pathomechanism of Parkinson's disease. J Chromatogr B Biomed Sci Appl, 2000; 746(2):297-304.

Papadoyannis IN, Samanidou VF, Nitsos CC. Simultaneous determination of nitrite and nitrate in drinking water and human serum by high performance anion-exchange chromatography and uv detection. J Liq Chromatogr \& Relat Technol, 1999; 22(13):2023-41.

Porsolt RD, Le Pichon M, Jalfre M. Depression: a new animal model sensitive to antidepressant treatments. Nature, 1977; 266(5604): $730-2$.

Radwan O, Ahmed RF. Amendment effect of resveratrol on diclofenac idiosyncratic toxicity: Augmentation of the anti-inflammatory effect by assessment of Arachidonic acid and IL-1beta levels. J Appl Pharm Sci 2016; 6(12):170-7.

Rodriguez Lanzi C, Perdicaro DJ, Antoniolli A, Fontana AR, Miatello RM, Bottini R, Vazquez Prieto MA. Grape pomace and grape pomace extract improve insulin signaling in high-fat-fructose fed ratinduced metabolic syndrome. Food Funct, 2016; 7(3):1544-53.

Ryan JP, Sheu LK, Critchley HD, Gianaros PJ. A neural circuitry linking insulin resistance to depressed mood. Psychosom Med, 2012; 74(5):476-82.

Sadi G, Konat D. Resveratrol regulates oxidative biomarkers and antioxidant enzymes in the brain of streptozotocin-induced diabetic rats. Pharm Biol, 2016; 54(7):1156-63.

Saleh DO, El Awdan SA, Abdel Jaleel GA, Ahmed RF. Resveratrol attenuates hepatic complications associated with insulin resistance: implications on hepatic HAIR, LAIR, cell energy and DNA fragmentation. J Appl Pharm Sci, 2017; 7(8):20-7.

Scranton R, Cincotta A. Bromocriptine - unique formulation of a dopamine agonist for the treatment of type 2 diabetes. Expert Opin Pharmacother, 2010; 11(2):269-79.

Sicinska P, Pytel E, Macczak A, Koter-Michalak M. [The use of various diet supplements in metabolic syndrome]. Postepy Hig Med Dosw (Online), 2015; 69:25-33.
Szkudelski T, Szkudelska K. Resveratrol and diabetes: from animal to human studies. Biochim Biophys Acta, 2015; 1852(6):1145-54.

Trinder P. Determination of blood glucose using an oxidaseperoxidase system with a non-carcinogenic chromogen. J Clin Pathol, 1969; 22(2):158-61

Weinberger JF, Raison CL, Rye DB, Montague AR, Woolwine BJ, Felger JC, Haroon E, Miller AH. Inhibition of tumor necrosis factor improves sleep continuity in patients with treatment resistant depression and high inflammation. Brain Behav Immun, 2015; 47:193-200.

Wong ML, Inserra A, Lewis MD, Mastronardi CA, Leong L, Choo J, Kentish S, Xie P, Morrison M, Wesselingh SL, Rogers GB, Licinio J. Inflammasome signaling affects anxiety- and depressive-like behavior and gut microbiome composition. Mol Psychiatry, 2016; 21(6): 797-805.

Yin QQ, Pei JJ, Xu S, Luo DZ, Dong SQ, Sun MH, You L, Sun ZJ, Liu XP. Pioglitazone improves cognitive function via increasing insulin sensitivity and strengthening antioxidant defense system in fructosedrinking insulin resistance rats. PLoS One, 2013; 8(3):e59313.

Yoshida T. Determination of reduced and oxidized glutathione in erythrocytes by high-performance liquid chromatography with ultraviolet absorbance detection. J Chromatogr B Biomed Appl, 1996; 678(2):157-64.

Zhang F, Shi JS, Zhou H, Wilson B, Hong JS, Gao HM Resveratrol protects dopamine neurons against lipopolysaccharide-induced neurotoxicity through its anti-inflammatory actions. Mol Pharmacol, 2010; 78(3):466-77.

How to cite this article:

Ahmed RF, El Awdan SA, Abdel Jaleel GA, Saleh DO, Ahmed Farid OAH. Correlation between brain neurotransmitters and insulin sensitivity: Neuro-preservative role of resveratrol against high fat, high fructose-induced insulin resistance. J Appl Pharm Sci, 2020; 10(02):026-036. 